\title{
Mathematical Modeling of Shear Stress and Direct Shear Test for Compressible Soil: Case of Soil Bordering the Wouri River
}

\author{
Michael Soup Teoua Ouagni ${ }^{*}$, François Ngapgue ${ }^{2}$, Fabien Kenmogne ${ }^{3}$, \\ Alain Soup Tewa Kammogne ${ }^{4}$, Simon Ngoh Koumi ${ }^{5}$
}

${ }^{1}$ Dschang School of Science and Technology (DSST), Department of Physics, Mechanical Unit of Research and Modeling Physical Systems, Energy-Mechanic, University of Dschang Cameroon, Dschang, Cameroon

${ }^{2}$ Department of Civil Engineering; Fotso Victor Institute of Technology, University of Dschang, Bandjoun, Cameroon

${ }^{3}$ Department of Civil Engineering, Higher Teacher Training College of Technical Education, University of Douala, Douala,

Cameroon

${ }^{4}$ Laboratory of Condensed Matter, Electronics and Signal Processing (LAMACETS), Faculty of Sciences, University of Dschang,

Dschang, Cameroon

${ }^{5}$ Department Thermal Engineering and Energy, Douala University Institute of Technology, Douala, Cameroon

Email: *ouagniteoua@yahoo.fr

How to cite this paper: Ouagni, M.S.T. Ngapgue, F., Kenmogne, F., Kammogne, A.S.T. and Koumi, S.N. (2021) Mathematical Modeling of Shear Stress and Direct Shear Test for Compressible Soil: Case of Soil Bordering the Wouri River. World Journal of Engineering and Technology, 9, 385-406. https://doi.org/10.4236/wjet.2021.93027

Received: March 11, 2021

Accepted: July 13, 2021

Published: July 16, 2021

Copyright $\odot 2021$ by author(s) and Scientific Research Publishing Inc. This work is licensed under the Creative Commons Attribution International License (CC BY 4.0).

http://creativecommons.org/licenses/by/4.0/

cC) (i) Open Access

\begin{abstract}
This paper focuses on the development of the mathematical model of shear stress by direct shear test for compressible soil of the littoral region, which will be a great tool in the hand of geotechnical engineers. The most common use of a shear test is to determine the shear strength which is the maximum shear stress that a material can withstand before the failure occurs. This parameter is useful in many engineering designs such as foundations, roads and retaining walls. We carried out an experimental laboratory test of ten samples of undisturbed soil taken at different points of the border of Wouri river of Cameroon. The samples were collected at different depths and a direct shear test was conducted. The investigations have been performed under constant vertical stresses and constant sample volume with the aim to determine the frictional angle and the cohesion of the compressible soil which are so important to establish the conditions of buildings stability. Special care was taken to derive loading conditions actually existing in the ground and to duplicate them in the laboratory. Given that the buildings constructed in this area are subjected to settlement, landslide, and punch break or shear failure, the cohesion and the frictional angle are determined through the rupture line after assessed the mean values of the shear stress for the considered ten samples. The bearing capacity of the soil, which is the fundamental soil parameter, was calculated. From the laboratory experimental results, the least squared me-
\end{abstract}


thod was used to derive an approximated mathematical model of the shearing stress. Many optimizations methods were then considered to reach the best adjustment.

\section{Keywords}

Direct Shear Test, Normal and Critical Stresses, Frictional Angle, Bearing Capacity, Mathematical Model

\section{Introduction}

Coastal regions have been always attractive strategic sites for construction projects. The great property of the soil in these regions is the compressibility of its structure [1] [2]. Moreover, because of their proximity to the sea, border areas are strategic implantation for both persons and companies [3] [4] [5]. Many borders constructions have been made possible after both earth embankment and compaction. In many cases, the water courses affect the surrounding soils and make them unfit to be used as the foundation stone and sometimes require a special treatment before use [6]. Many authors have focused their researches on the theoretical and experimental content analyses of soil properties. To name just a few, Kozicki et al. [7] proposed discrete modeling results of a direct shear test for granular materials versus finite element results, in which the comparison of results obtained for both discrete and finite elements calculations is made, while Xia and coworkers[8] developed a shear behavior of rock joints under constant normal stiffness (CNS) boundary condition. They limit their studies on 48 groups of shear tests on plaster specimens replicated from three rough rock joints, and as results the effects of joint roughness, normal stiffness, and initial normal stress on mechanical characteristics of joints were significantly investigated. Recently Liu and collaborators [9] proposed a new device designed to make direct shear test on sandstone using a constant normal load, while Larsson and Flansbjer [10] developed an approach to compensate the influence of the system normal stiffness in CNS direct shear tests. In their obvious works, they introduced the effective normal stiffness approach applicable to closed-loop control systems, and they nest established the effects of the system normal stiffness on the applied normal load. More recently, Ouagni et al. [11] proposed a direct oedometer test to show that the soil of coast area is highly compressible and out of the phenomenon of shrinkage-swelling that creates differential settlement on construction.

Despite the above mentioned works, there is not enough consideration on direct shear tests for compressible soil issues to the best of our knowledge which still remains challenging and thus deserves more dissemination. It's worth noting that the coastal region in general, and particularly the Douala town bordering the Wouri river of Cameroon, is congested and the population density is too high. This is why inhabitants and companies assault these areas in order to set buildings and houses. Among some of soil tests necessary to be made before any 
construction project, there is the bearing capacity test through the penetrometer, and in coastal area, it gives very low results (around 0.01 Mpa), leading these areas to be classified as non-constructible, highlighting then the interest of the present work, which aims to give more details about the results obtained for the compressible soils. One may wonder whether some of soils properties can be deduced through mathematical formulations.

In the present study, a laboratory test was conducted to determine the bearing capacity of the soil which is helpful to dimension structural elements such as footings. The results of the shear test at ten points collected at different depths in the area were then analyzed. Accurate determination of the shear strength parameters (angle of internal friction and cohesion) is a major interest in the design of different geotechnical structures. We recall that the shear strength is the main engineering property of soil, helping engineers to ensure the soil mass stability under structural loads [12] [13]. These parameters can be found either in laboratory or on the site. Then understand and master soil behavior is a great challenge in the civil engineering field. In fact, soil can be considered as an assembly of elements [14] [15] [16], with the presence of voids between particles, which contain water and/or air, making the soil a three-phase material [17] [18] [19]. When collecting samples, we observed multiple layers of soil with different colors and the succession of its structure in its profile, as illustrated in Figure 1. Granular classification enables engineers to predict the soil's behavior, which has important implications for both the mechanical and erosion properties of sediment [20]. The physical properties of the soil of Douala River can be easily found in [21]. According to these obvious reasons, this study aims to determine the average value of the bearing capacity (a function of the depth $h$ ) of the soil through the direct shearing test $(C, \varphi)$ by applying the Terzaghi formula, which would be a hand use tool for engineers carrying out a project in those boarders and which could help the town planners in their land use plan in the region. This paper is organized as follows: in the next section we present the materials and method to determine the mechanical parameters of the soil; then follows the computational principles of the direct shear test. In Section 3 we present the

\begin{tabular}{|c|l|}
\hline \multicolumn{2}{|c|}{ Point $\mathrm{P}_{1}$} \\
\hline Depth/Soil nature & Soil log \\
\hline $0-1.50 \mathrm{~m}$ & \\
Reddish clay & \\
\hline $1.50-6.50 \mathrm{~m}$ & \\
Reddish sandy clay & \\
& \\
\hline $6.00-8.00 \mathrm{~m}$ & \\
Yellowish sandy clay & \\
& \\
& \\
\hline
\end{tabular}

Figure 1. Sample of soil $\log$ position $\mathrm{P}_{1}$. 
results and discussions. In Section 4 we introduce the mathematical modeling and end up in the final section by our conclusions.

\section{Materials and Methods}

\subsection{Materials and Sampling}

The data under considerations in the present work was based on ten samples of undisturbed soil collected at different depths of the coast, positioned at locations points $P_{i}, i=1,2, \cdots, 10$ and distanced from each other by ten to fifteen meters, with their geographical location indicated in Figure 2. The inner dimensions of samples are $60 \mathrm{~mm} \times 60 \mathrm{~mm}$ in plan which was also the inner dimension of shear box. The thickness of box was about $50 \mathrm{~mm}$ while the thickness of sample is $25 \mathrm{~mm}$. It is important to mention that the increasing of the population density in the center region impulses population to build many stores, which impacts on the load acted on the soil. Therefore in addition to the penetrometer test necessary for constructions, civil engineers need to go deeper in soil investigations and carry on the direct shear test. Soil samples are then collected using a variety of approaches and tools subjecting on the depth of the desired sample and the soil type. Near-surface soils are easily sampled using a trowel, and scoop. At greater depths, continuous flight auger (screw) consisted of a trier and a "T" handle is used, After collecting the samples, we brought them to the laboratory to perform the test, via the phases and process which can be found in [22] [23], the US and UK standards which define how the test should be performed being ASTM D3080, AASHTO T236 and BS 1377-7:1990 respectively.

For each sample collected at each point as enumerated above, we took three samples and applied three different loads

$$
\sigma \in\{0.1 \mathrm{Mpa}, 0.2 \mathrm{Mpa}, 0.3 \mathrm{Mpa}\},
$$

Which are normal stresses and next we plotted for each of the ten points three curves, corresponding each one to the corresponding normal stress. For each point, we found the breaking stress $\tau_{r i}$ and computed the mean value:

$$
\tau_{r 1}=\sum_{i=1}^{10} \frac{\tau_{1 r i}}{10}, \tau_{r 2}=\sum_{i=1}^{10} \frac{\tau_{2 r i}}{10}, \tau_{r 3}=\sum_{i=1}^{10} \frac{\tau_{3 r i}}{10} .
$$

Therefore having three breaking stresses $\left(\tau_{r 1}, \tau_{r 2}, \tau_{r 3}\right)$ corresponding to the three normal stresses at each point, we plotted the coulomb line and we extended to the y-axis. Then we obtained the cohesion $c_{i}$ of the soil, while the frictional angle $\varphi_{i}$ is given by the slope of the coulomb line. This frictional angle as well as the cohesion of the compressible soil is given by their mean values as follows:

$$
\begin{gathered}
\varphi_{i}=\arctan \left(\frac{\Delta \tau}{\Delta \sigma}\right), \varphi_{m}=\sum_{i=1}^{10} \frac{\varphi_{i}}{10} \\
C_{m}=\sum_{i=1}^{10} \frac{c_{i}}{10} .
\end{gathered}
$$

To model the function which can best represent the graph of the shear stress, 
the least squared method is used to adjust the results obtained by experiment.

\subsection{Fieldwork and Localization of the Site of Study}

The main concern for this ancient soil strength test is to keep intact the samples until the laboratory. Next, one uses the most open method to assess the resistance at the interface among two frames. The geographical coordinates of the area where soil samples are collected is shown in Table 1.

\subsection{Computation Principles for Direct Shear Test}

The principle of test is illustrated in Figure 3, where the soil sample, confined inside the upper and lower rigid boxes $(60 \mathrm{~mm} \times 60 \mathrm{~mm})$, is subjected to the normal load $F=\sigma A$ and is sheared by the shear force $T=\tau A$, A being the surface where forces are applied. All the above samples are tested after setting the apparatus, under varying normal loads given by Equation (1), to determine

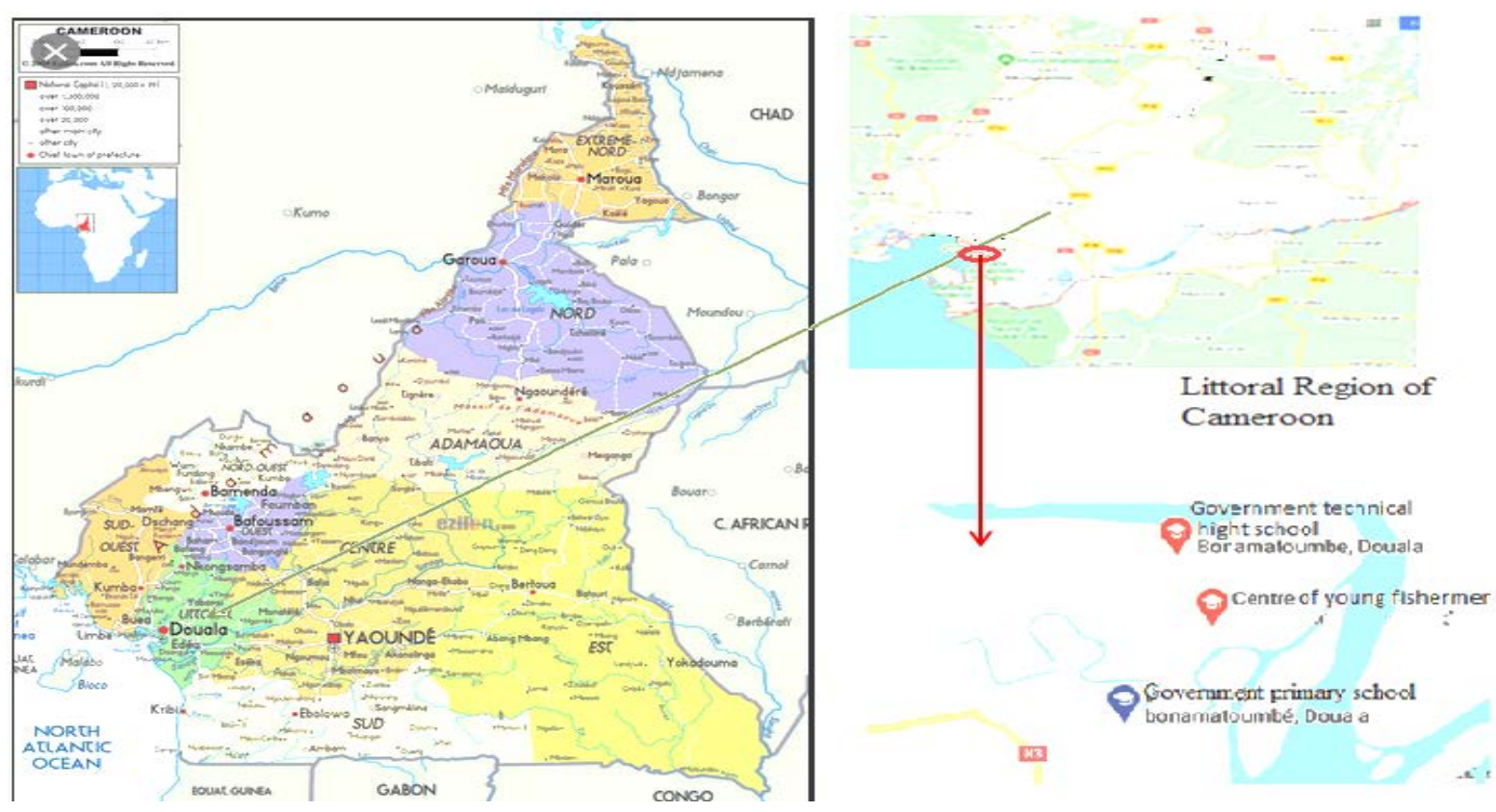

(a)

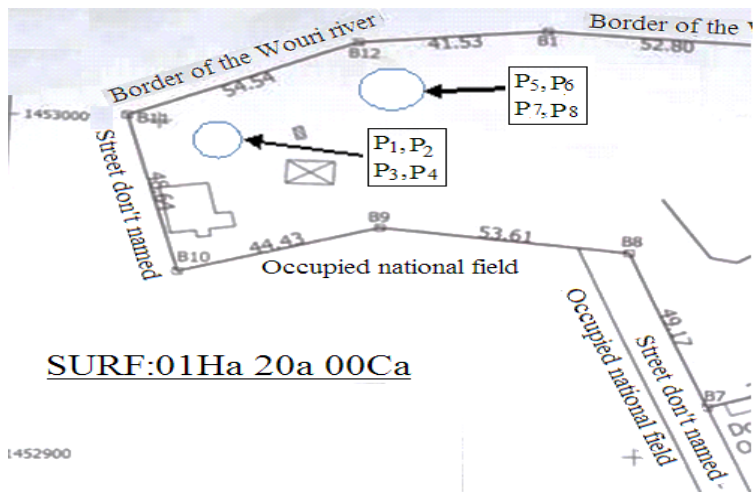

(b)

Figure 2. (a) Location of the study area in the Littoral region of Cameroon. (b) Points of collect samples. 
Table 1. Geodetic coordinates of the site location.

\begin{tabular}{ccc}
\hline & \multicolumn{2}{c}{ Geodetic Coordinates } \\
\cline { 2 - 3 } Points & $\mathrm{X}$ & $\mathrm{Y}$ \\
\hline $\mathrm{B}_{1}$ & $574,385.842$ & $453,192.507$ \\
$\mathrm{~B}_{2}$ & $574,438.544$ & $453,189.306$ \\
$\mathrm{~B}_{3}$ & $574,461.837$ & $453,186.142$ \\
$\mathrm{~B}_{4}$ & $574,479.913$ & $453,180.613$ \\
$\mathrm{~B}_{5}$ & $574,439.645$ & $453,089.746$ \\
$\mathrm{~B}_{6}$ & $574,448.873$ & $453,086.019$ \\
$\mathrm{~B}_{7}$ & $574,418.699$ & $453,075.667$ \\
$\mathrm{~B}_{8}$ & $574,402.942$ & $453,122.245$ \\
$\mathrm{~B}_{9}$ & $547,349.751$ & $453,128.885$ \\
$\mathrm{~B}_{10}$ & $574,307.644$ & $453,114.699$ \\
\hline
\end{tabular}

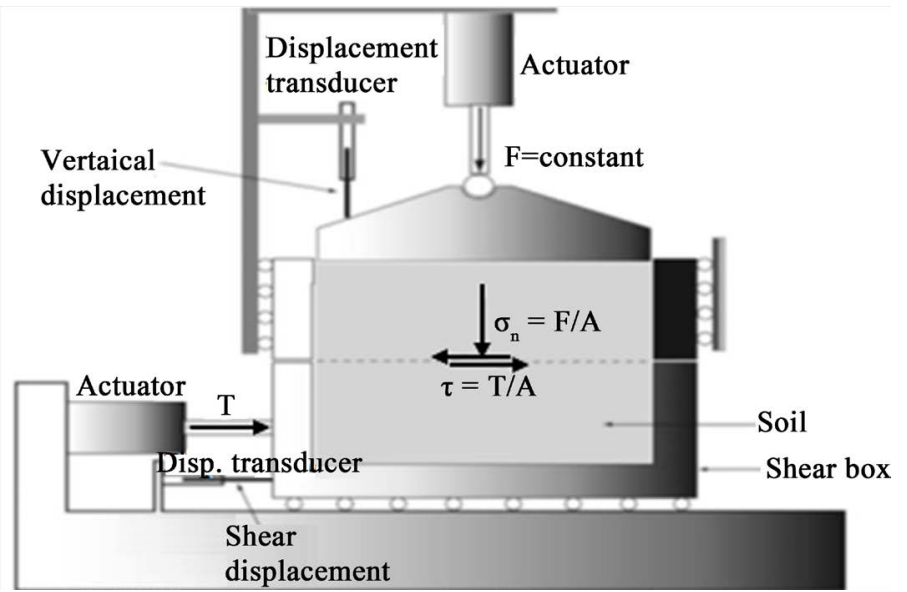

Figure 3. Direct shear test principle [24].

the effects upon shear resistance and displacement, and strength properties such as Mohr strength envelope. As results, the maximum shear stresses versus the vertical (normal) confining stresses are plotted for each sample. Next the maximum shear stress $\left(\tau_{r 1}, \tau_{r 2}, \tau_{r 3}\right)$ known as critical shear stress or breaking stress is obtained for a specific vertical confining stress. From the plot, a straight-line approximation of the Mohr-Coulomb failure envelope curve is drawn. The cohesion $C$ and the friction angle $\varphi$ are then computed from the shear stress equation:

$$
\tau=\tan (\varphi) \sigma_{n}+C
$$

\subsection{Experimental Overview}

A civil engineer needs to watch out damages on a structure and master correctly all parameters that can influence the structure stability. When a portion of soil is 
loaded (as illustrated in Figure 4), the ruin can occur by settlement, punching or shearing [25]. Both frictional angle and the cohesion are parameters which are affected.

Knowing these parameters, we assess the bearing capacity of the soil, from where we deduce the ultimate strength called allowable bearing. The cost and safety of any structural building are thoroughly relevant for these values, which has a direct impact of the dimensioning of structural elements and the reinforcement.

As far as cohesion and internal friction are concerned, both simple and elaborated including laboratory methods of determining soil parameters have been developed by geotechnical researchers and engineers (e.g. [26] [27]). Let us mention that the shear stress of soil can also be determined through triaxial compressing test [28]. The most commonly applied field tests are vane shear test, standard penetration test (SPT), and cone penetration test (CPT) and so on [29] [30]. The mechanical parameters $(C, \varphi)$ depends on the size of particles. In this work, the direct shear test was considered due to its reliability and simplicity [31], and the experimental setup is shown in Figure 5.

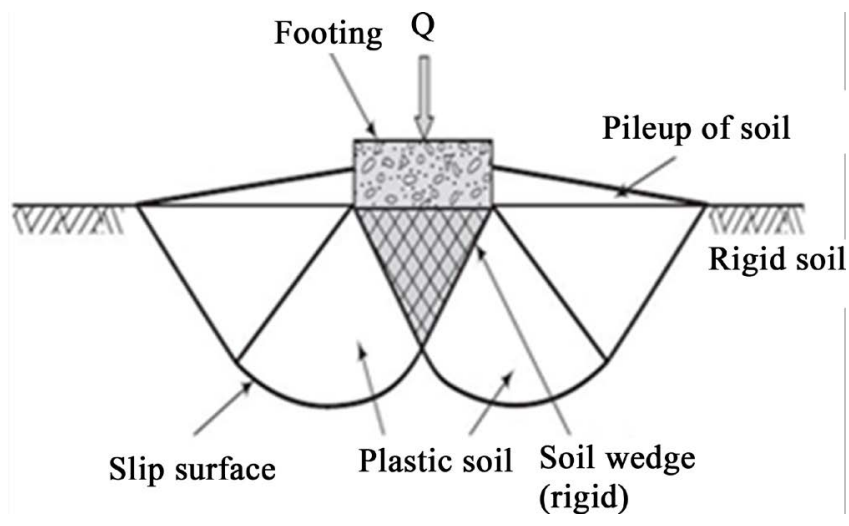

Figure 4. Failure pattern under a loaded footing [24].

Dial gauge (Vertical displacement)

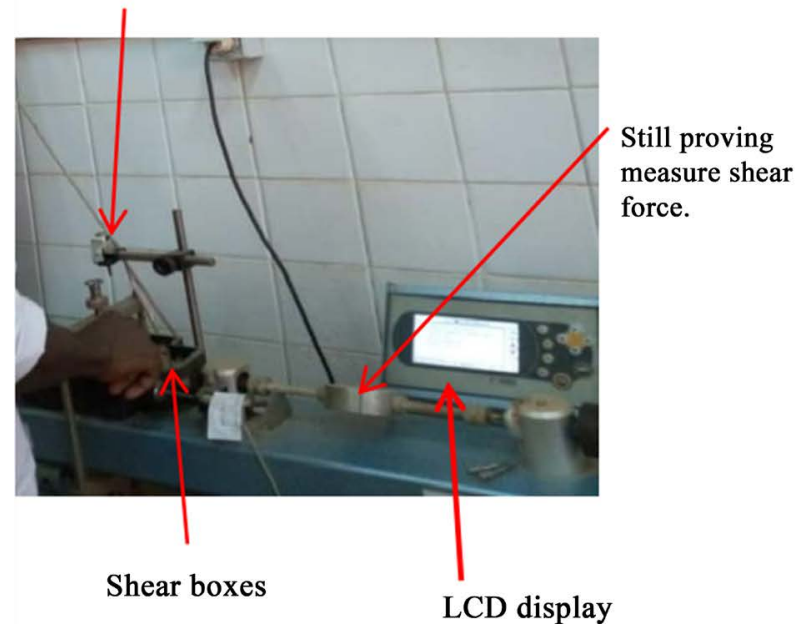

Figure 5. Experiment setup.

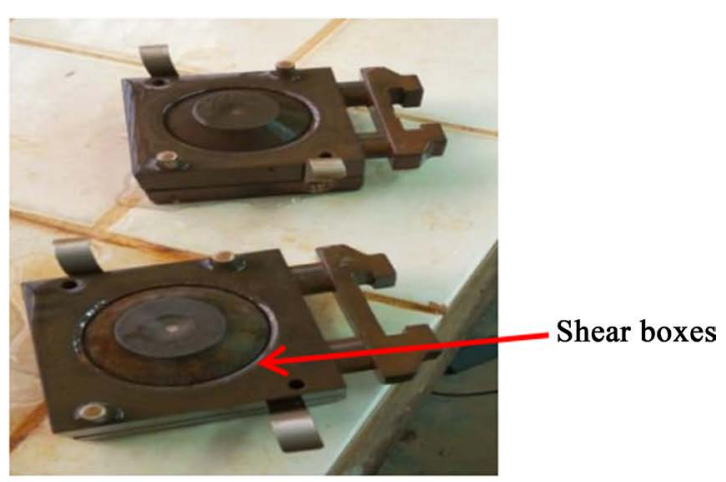




\section{Results and Discussions}

\subsection{Preliminary}

This section presents results and discussions about shearing test for coastal areas, which is an experiment to determine the mechanical characteristics of the soil as far as cohesion and frictional angle are concerned, as described in Section 2. For illustrative purpose, Figure 6 depicts the shearing stress versus shearing displacement from where we clearly observe that the evolution is linear and reaches the critical value which is a shear stress of the soil. We then have $\left(\tau_{r 1}, \tau_{r 2}, \tau_{r 3}\right)$ representing the critical stress for the above loads given by Equation (1). Following the same process, we have the shear stress for the other samples points (P3...P10) as shown in Figure 7, while the shear stress for the ten points location and their means values are given in Table 2. Therefore, from these values we deduce the values of cohesion and frictional angle $(C, \varphi)$ of the soil at these positions as shown in Figure 8 for illustrative purpose for the ten points. The same approaches were applied for the rest of points P3 to P10 and the results are presented in Figure 9.

The means values of mechanicals properties of the soil studied are shown in Table 3 for all the ten points. Statistically, we exploit those values to determine the mean values of cohesion and frictional angles of the particles of soil. Having the standard deviation in good range and the value of the correlation $R$ tends to 1 ( $R^{2}$ in Figure 9) and considering the individual value, we then determine the frictional angle and the cohesion of the compressible soil of the border coast which for our case is Wouri river of Cameroon.

$$
C=0.0339 \mathrm{Mpa}, \varphi=28.846^{\circ}
$$

From the curves previously obtained (Figure 8, Figure 10) we can determine the mean values for the breaking stress for each normal stress:

$$
\tau_{r 1 m}=0.895 \times 10^{-1} \mathrm{MPa}, \tau_{r 2 m}=1.482 \times 10^{-1} \mathrm{MPa}, \tau_{r 3 m}=2.001 \times 10^{-1} \mathrm{MPa}
$$

By using again the above normal stresses for the entire direct shearing test, we
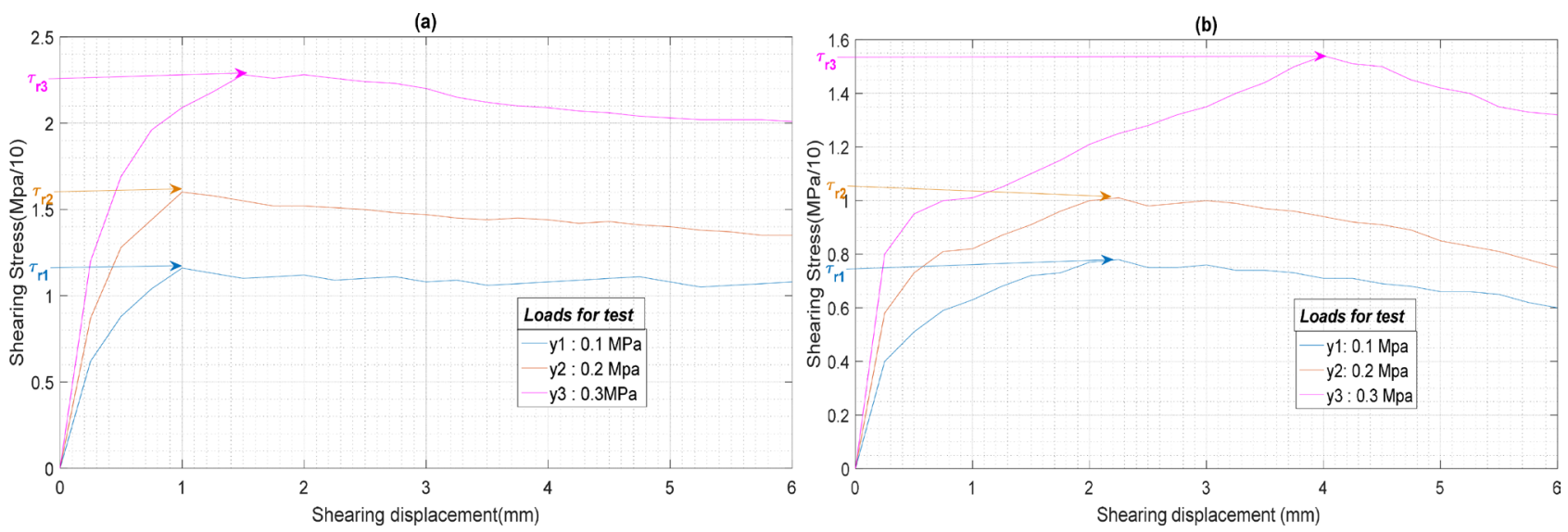

Figure 6. Shear stress at $\mathrm{P} 1$ and $\mathrm{P} 2$, tangential stress versus shearing displacement. at point (a) $\mathrm{P} 1: \quad\left(\tau_{r 1}, \tau_{r 2}, \tau_{r 3}\right)=(1.16,1.60,2.28)$ $10^{-1} \mathrm{Mpa}$; (b) at point P2: $\left(\tau_{r 1}, \tau_{r 2}, \tau_{r 3}\right)=(0.78,1.01,1.54) 10^{-1} \mathrm{Mpa}$. 

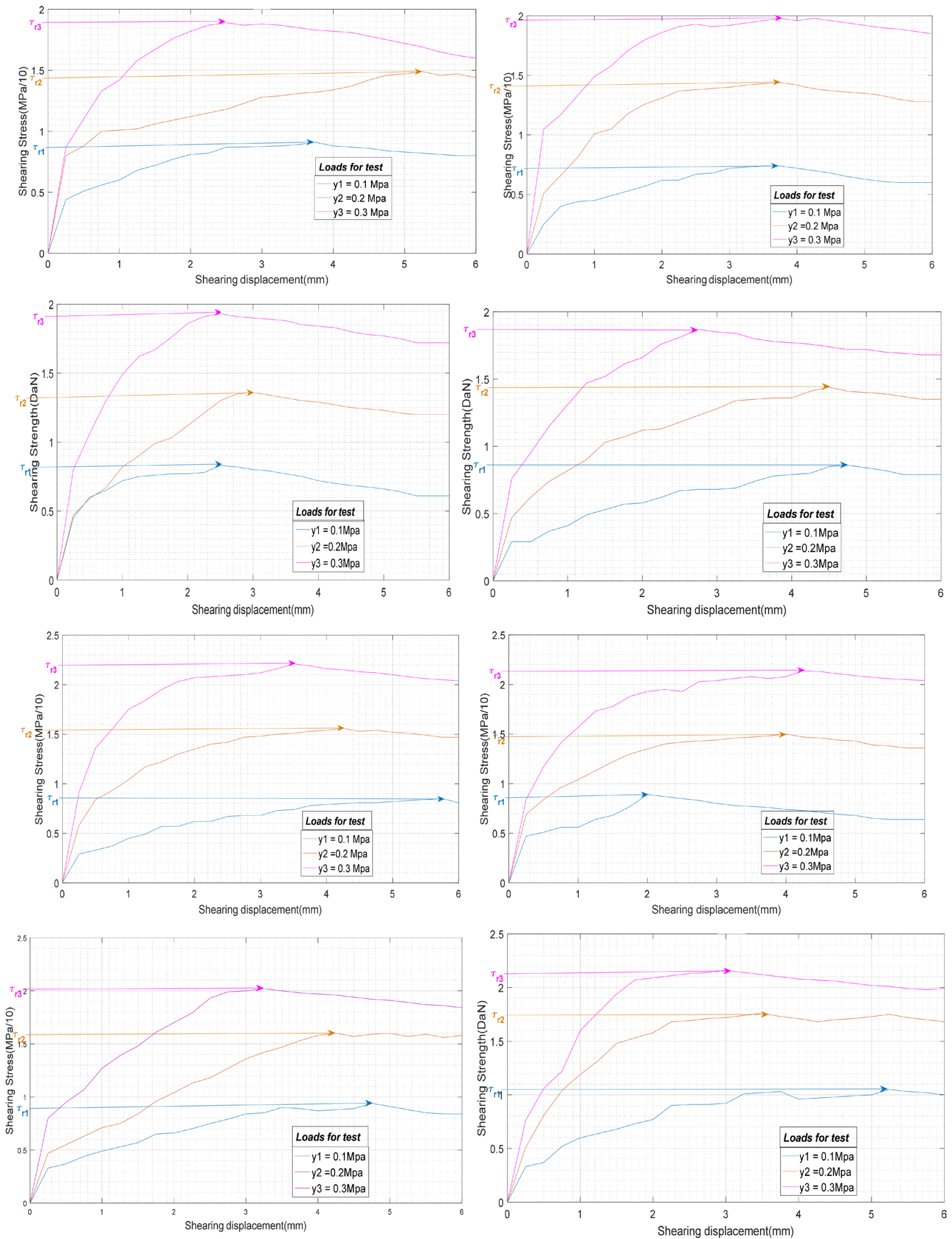

Figure 7. Shear stress (peak) at points $\mathrm{P} 3$ to P10, tangential stress versus shearing displacement. 
Table 2. Shear stress at different points location according to the normal load and their means values.

\begin{tabular}{ccccccccccccc}
\hline $\begin{array}{c}\text { Points } \\
\text { location }\end{array}$ & $\begin{array}{c}\text { Normal } \\
\text { Stress } \\
(\mathrm{MPa} / 10)\end{array}$ & $\mathbf{P}_{1}$ & $\mathbf{P}_{2}$ & $\mathbf{P}_{3}$ & $\mathbf{P}_{4}$ & $\mathbf{P}_{5}$ & $\mathbf{P}_{6}$ & $\mathbf{P}_{7}$ & $\mathbf{P}_{8}$ & $\mathbf{P}_{9}$ & $\begin{array}{c}\text { Means values of } \\
\mathbf{P}_{10}\end{array}$ & $\begin{array}{c}\text { the breaking stress } \\
\text { (bar) }\end{array}$ \\
\hline $\begin{array}{c}\text { Breaking stress } \\
(\mathrm{MPa} / 10)\end{array}$ & 1 & 1.16 & 0.78 & 0.91 & 0.74 & 0.83 & 0.86 & 0.85 & 0.89 & 0.91 & 1.09 & 0.895 \\
& 2 & 1.60 & 1.01 & 1.49 & 1.44 & 1.36 & 1.44 & 1.56 & 1.50 & 1.60 & 1.76 & 1.482 \\
& 3 & 2.28 & 1.54 & 1.89 & 1.98 & 1.93 & 1.87 & 2.21 & 2.14 & 2.02 & 2.16 & 2.002 \\
\hline
\end{tabular}
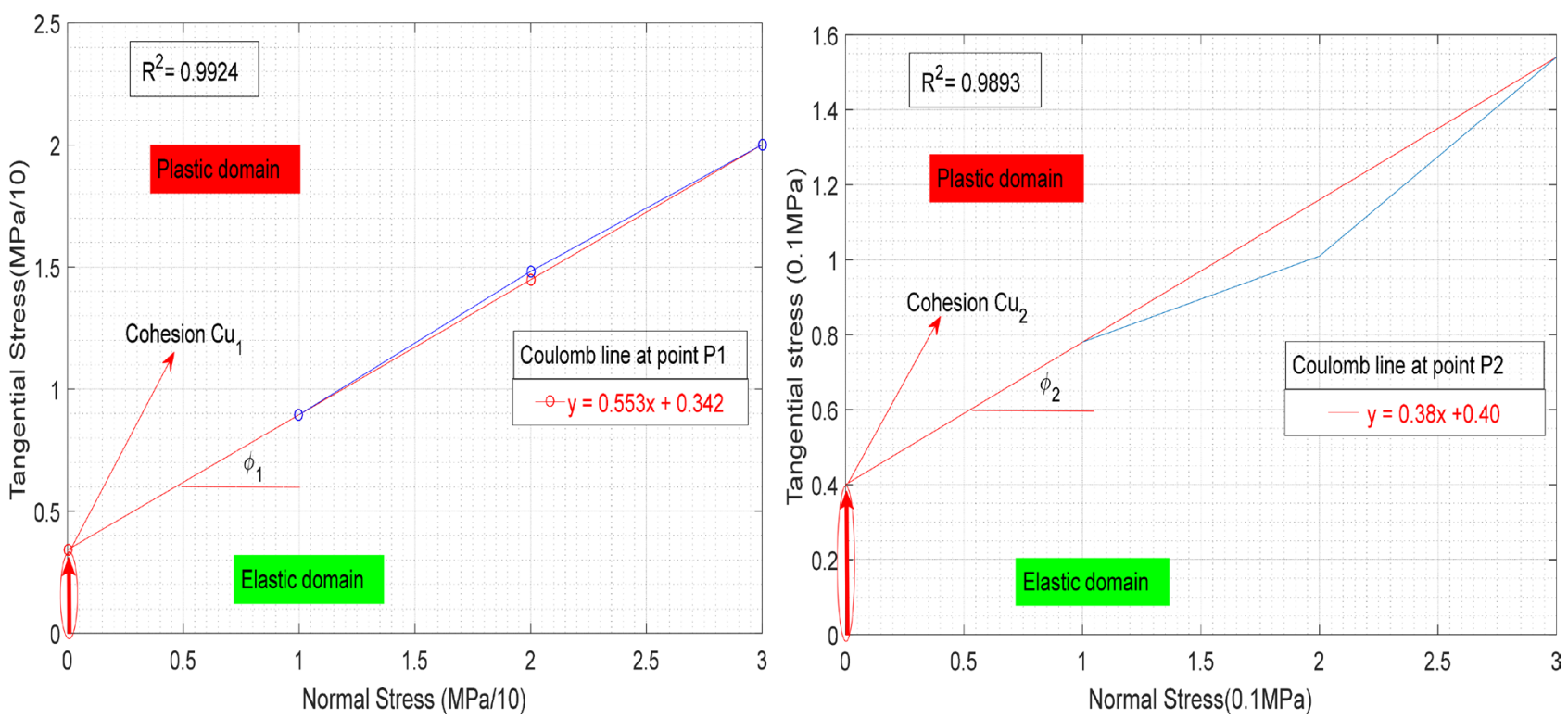

Figure 8. Morh Coulomb straight line at two locations points, P1: (a): $C=0.60, \varphi_{1}=29.65^{\circ}, R^{2}=0.9924 ; \mathrm{P} 2:(\mathrm{b}): C=0.40, \varphi_{2}=$ $20.820^{\circ}, R^{2}=0.9893$

Table 3. Mean values of frictional angle and cohesion for ten points with relevant density and moisture contents.

\begin{tabular}{|c|c|c|c|c|c|c|c|c|c|c|c|}
\hline Points & $\mathbf{P}_{1}$ & $\mathbf{P}_{2}$ & $\mathbf{P}_{3}$ & $\mathbf{P}_{4}$ & $\mathbf{P}_{5}$ & $\mathbf{P}_{6}$ & $\mathbf{P}_{7}$ & $\mathbf{P}_{8}$ & $\mathbf{P}_{9}$ & $\mathbf{P}_{10}$ & $\begin{array}{l}\text { Means } \\
\text { values }\end{array}$ \\
\hline $\begin{array}{l}\text { Natural moisture } \\
\text { contents (\%) }\end{array}$ & 27.800 & 27.800 & 21.300 & 30.800 & 21.000 & 17.300 & 23.900 & 23.300 & 21.300 & 26.300 & 24.080 \\
\hline $\begin{array}{l}\text { Wet density } \\
\left(\mathrm{kN} / \mathrm{m}^{3}\right)\end{array}$ & 1.590 & 1.800 & 1.460 & 1.550 & 1.600 & 1.730 & 1.710 & 1.490 & 1.580 & 1.510 & 1.602 \\
\hline Frictional angle $\left({ }^{\circ}\right)$ & 29.264 & 20.817 & 25.887 & 31.815 & 28.869 & 26.807 & 34.233 & 32.022 & 29.264 & 29.481 & 28.846 \\
\hline $\begin{array}{c}\text { Cohesion } \mathrm{Cu} \\
(\mathrm{MPa} / 10)\end{array}$ & 0.600 & 0.370 & 0.425 & 0.120 & 0.280 & 0.355 & 0.170 & 0.2650 & 0.340 & 0.465 & 0.339 \\
\hline
\end{tabular}

have plotted the Mohr Coulomb straight line failure stress vs normal stress, as shown in Figure 10 representing the direct shearing test of the soil with $\left(C_{m}, \varphi_{m}\right)$ as cohesion and frictional angle that are the means values. From Figure 8 , we deduce average values of the mechanical properties of the soil:

$$
C_{u m}=0.342 \text { bar }, \varphi_{m}=28.96^{\circ} \text {. }
$$

It is obvious to observe the similarity between these results and those obtained above (5 and 6). 

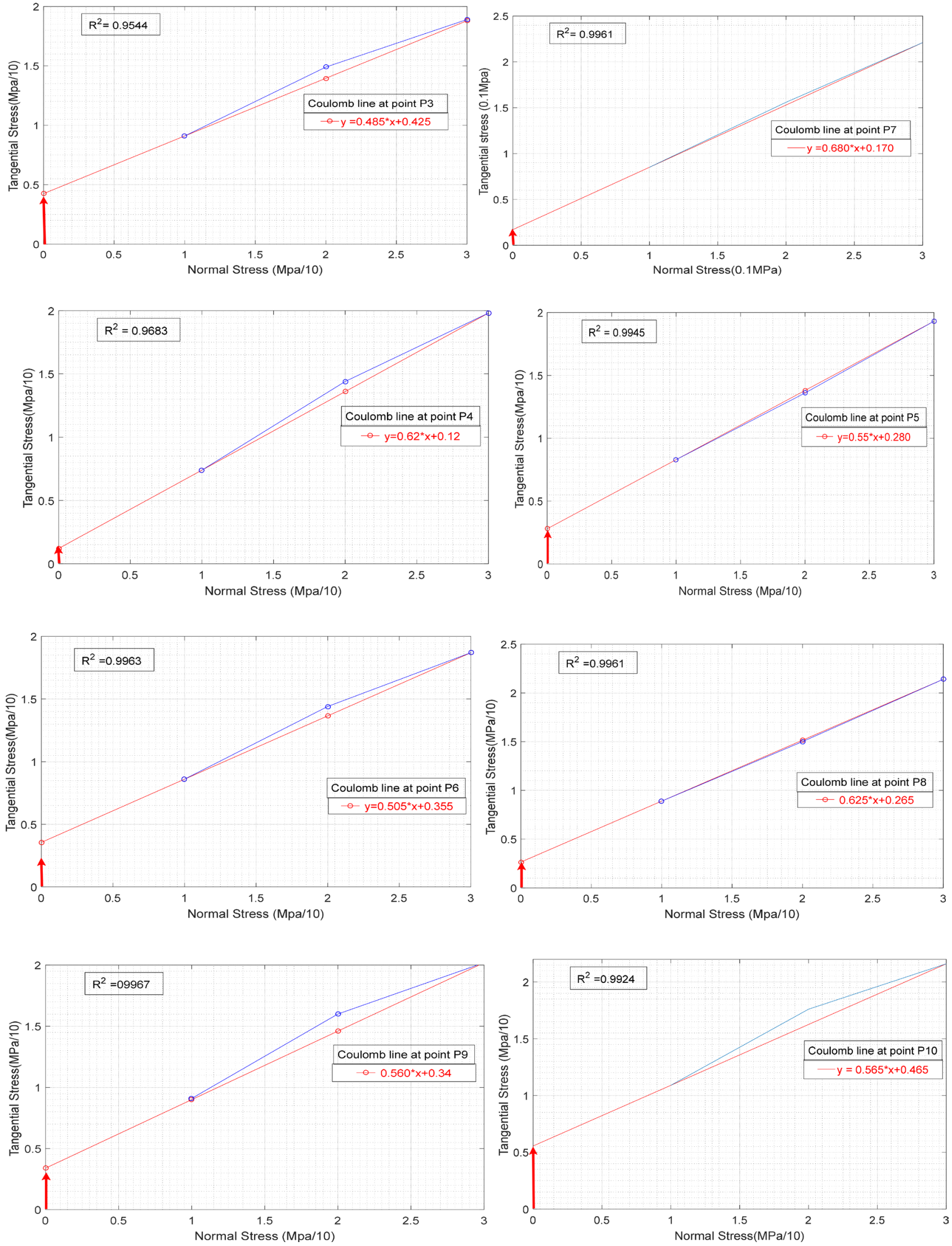

Figure 9. Morh Coulomb straight line at eigth locations points for P3 to P10 in which we can compute $c_{i}$ and $\varphi_{i}$. 


\subsection{Validation of Results}

Soils can be visibly known by their sizes ${ }^{x}$ as shown in Table 4 [1]. As shown in subsection 3-1, soil bordering the Wouri coast is a sort of clay melt with a low percentage of sand, with clay very soft, since its frictional angle verifies $26^{\circ} \leq \varphi \leq 32^{\circ}$ [24]. The sieve analysis is shown on Figure 11.

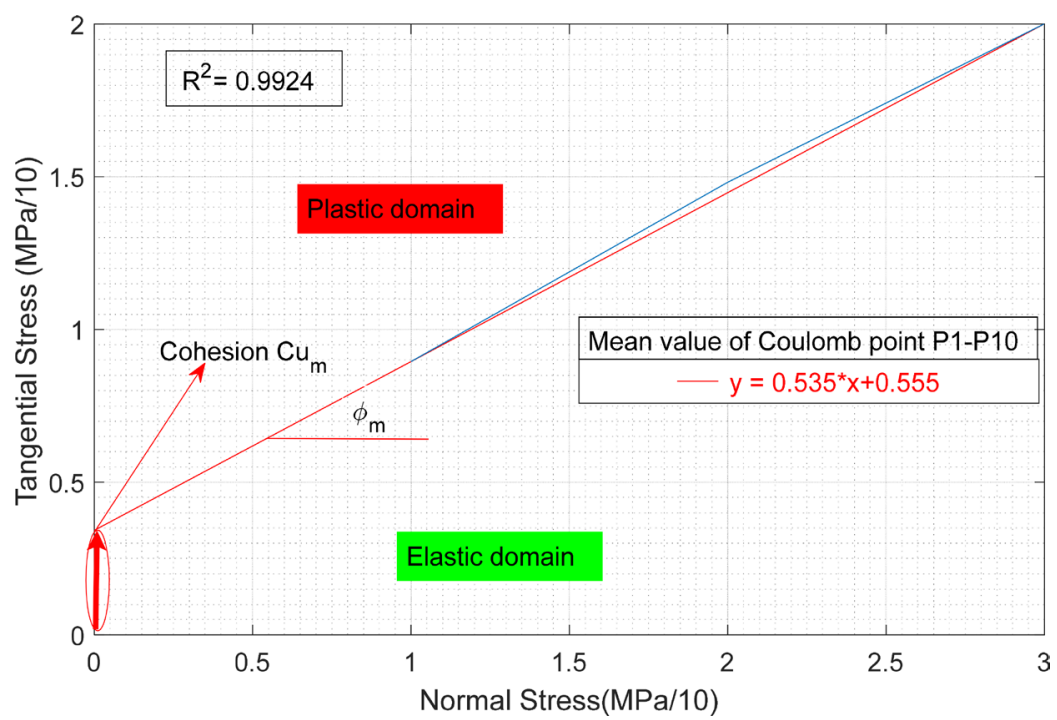

Figure 10. Plot of the direct shearing test of the soil for the ten points (P1...P10) considering the mean values.

Table 4. Classification of soil type based on particle sizes and shapes [1].

\begin{tabular}{ccccc}
\hline Soil type & Particle size & Particle shape $(\mathrm{mm})$ & Distinguishable with naked eye \\
\hline Gravel & $2-60$ & Granular & Obviously \\
Granular soil & Sand & $0.06-2$ & Granular & Easily \\
& Silt & $0.002-0.06$ & Granular & Barely \\
Cohesive soil & Clay & $<0.002$ & Flat plate & Impossible \\
\hline
\end{tabular}

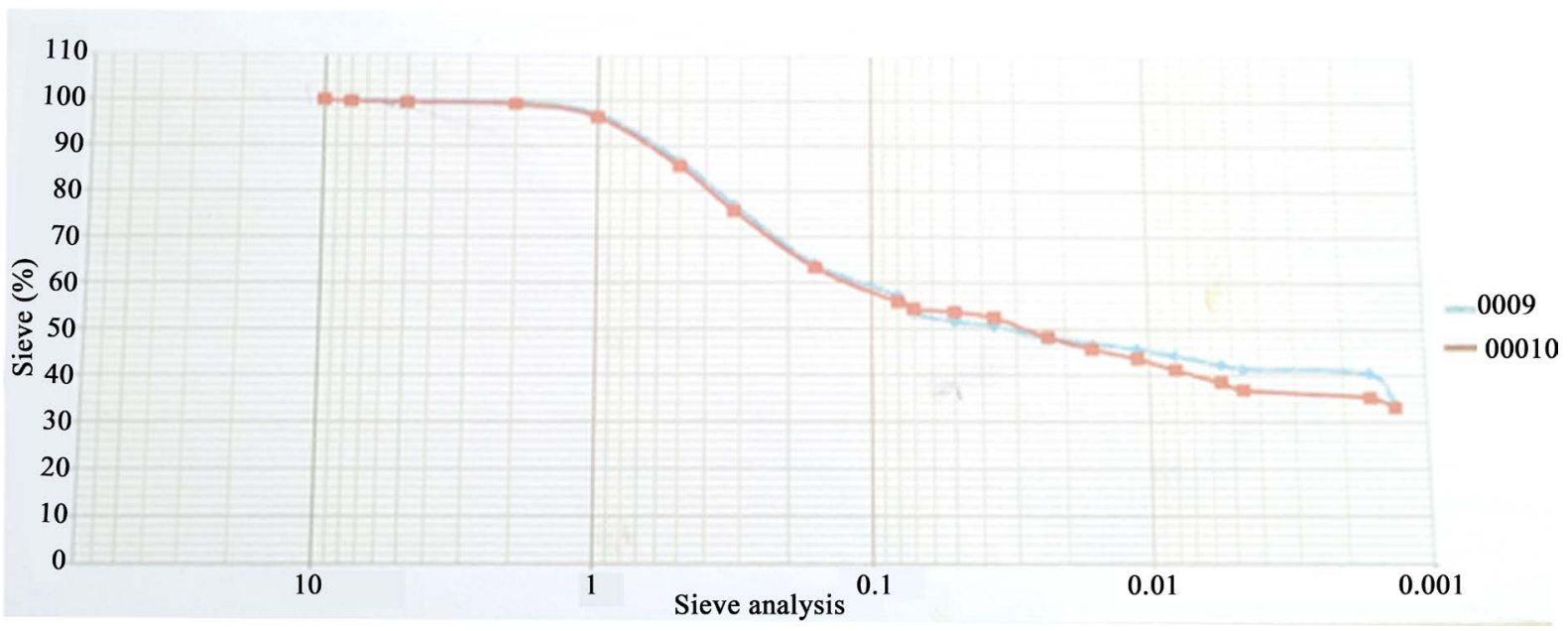

Figure 11. Particle size analysis of soil borders Wouri River. 
Frictional angle and contact force play major role in both soil and foundations classification. Soil of Wouri border of Douala has been recently classified as highly compressible (illites), medium clay according to the range of the compression index $\mathrm{Cc}$ [11] and is amongst the most important type of mineral clay. This type of soil can be easily rolled and molded. Shear failure takes place when both cohesive resistance and friction (stress and friction) are not sufficient (see Figure 12). Nevertheless, the normal effective stress rather than total (conventional) normal stress is ideal to evaluate the shear resistance.

As one can see from Figure 8, the relationship between $\tau_{\text {clay }}$ and $\sigma_{n}$ is the affine function, meaning that Equation (5) is satisfied.

As an example, if a structure with a gravity-based foundation is built on this site (see Figure 13), with the applied normal effective stress $\left(\sigma_{n}\right)$ and shear stress $(\tau)$ at location P5, $\sigma_{n}=180 \mathrm{kPa}$ and $\tau=102 \mathrm{kPa}$, respectively, as obtained experimentally. In order to evaluate whether the soil's shear stress is sufficient at location P5, From Equation (5), one can have $\tau_{\text {clay }}=180 \times \tan (28.96)+0.342 \times 10^{-4}=99.62 \mathrm{kPa}$. It is then obvious that, $\tau_{\text {clay }}<\tau$ and therefore, the shear stress of the soil is unsatisfactory, and the construction will collapse.

The failure criterion is often expressed by "Mohr-Coulomb failure criterion", also called coulomb line which describes the boundary between soil's linear-elastic and plastic behavior in terms of effective stress parameters, as shown in Figure 10 and Figure 11. It also shows the frontier between elastic and plastic domains (See Figure 8). We note that shear stress of clay is triggered even at zero normal effective stress when the past stress-strain history allows it. From the coulomb-straight-line shown in Figure 8, the extension of the straight-line on
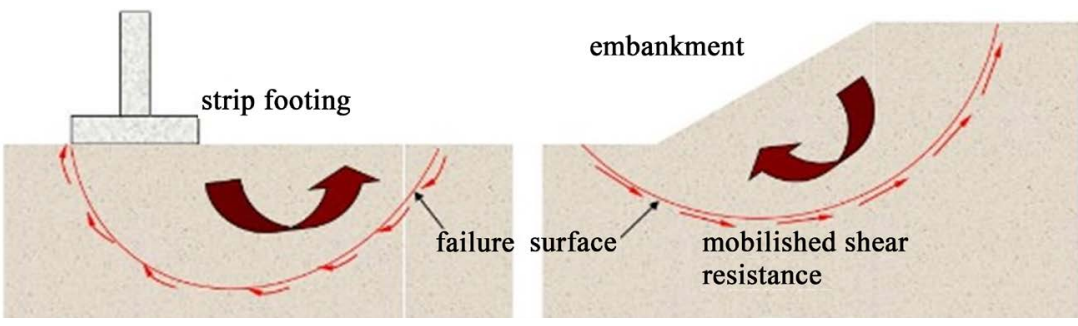

Figure 12. Shear failure in Foundation... [26].

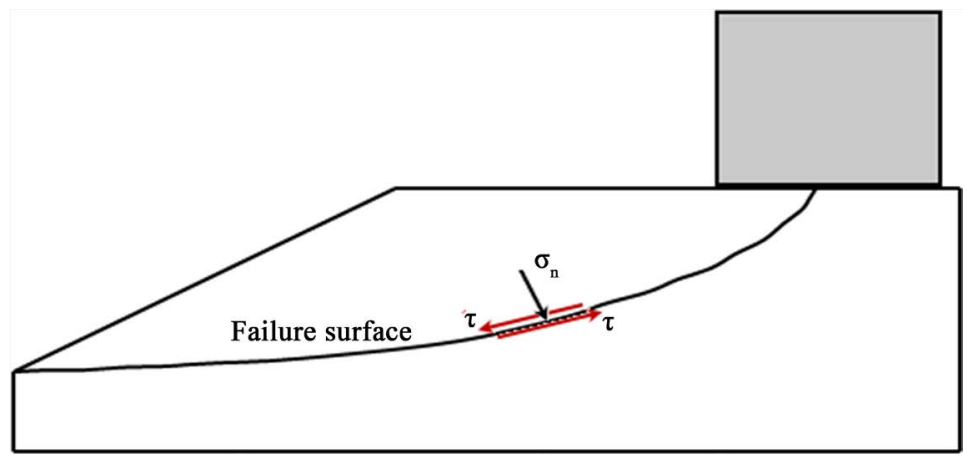

Figure 13. Illustration of shear stress of soils [24]. 
$y$-axis doesn't pass by the origin; proving the lower sand percentage in this soil. Both the mean values $\left(C_{u m}, \varphi_{m}\right)$ referred to the strength parameters of soils.

- Case of saturated clays, $\varphi^{\prime}=0$, leading to the undrained strength $\tau_{c l a y}=C^{\prime}$, Here, based on the method illustrated by Prandtl [32] to study the penetration of hard bodies into softer materials, Terzaghi [33] proposed that the bearing capacity of shallow foundations at a depth $\mathrm{h}$ measured from the ground surface can be determined as an ultimate effective pressure $q_{u}^{\prime}$ reflecting the general shear failure mode as shown in Figure 4.

$$
q_{u}^{\prime}=C N_{c} S_{c} d_{c} i_{c}+\gamma^{\prime} h N_{q} S_{q} d_{q} i_{q}+0.5 B^{\prime} \gamma^{\prime} N_{\gamma} S_{\gamma} d_{\gamma} i_{\gamma},
$$

$N_{c}, N_{q}, N_{\gamma}$ being constants representing the influence from unit weight, overburden pressure, and cohesion, respectively, and they are functions of friction angle of sands and can be checked from relevant geotechnical handbooks. (The reader can referred to the nomenclature presented in this document for details and can also have an excellent text in Ref. [34] [35]).

- Illustrative example

For rectangular footings, we denote $B$ and $L$ the width and the length respectively,

$$
S_{\gamma}=0.8, \quad S_{q}=1, \quad S_{c}=\left[1+\left(\frac{0.3 B}{L}\right)\right] .
$$

Due to the fact that the study was carried out at the boarder of the coast, when the underground water at a depth $D$ is below or above the footing, the effective unit weight of the soil in the third term may be replaced by a weighted average unit weight and (10) becomes:

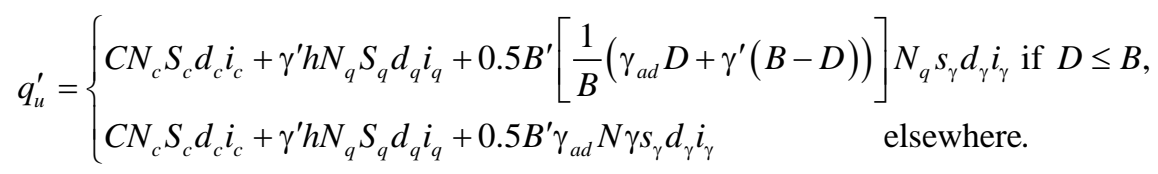

Equation (12) enables to calculate the bearing capacity of the soil and hence allowable bearing capacity at any depth $h$. Let us consider a classical case for the Equation (12) such as $D \leq B$. One obtains:

$$
\begin{gathered}
q_{u}^{\prime}=q_{u}^{\prime}(h)=\gamma^{\prime} N_{q} h+0.5 B \gamma^{\prime} N_{\gamma}+C N_{c}=\alpha h+\beta \\
\alpha=\gamma^{\prime} N_{q}, \quad \beta=0.5 B \gamma^{\prime} N_{\gamma}+C N_{c}
\end{gathered}
$$

Let's $h=2.00 \mathrm{~m}$. The characteristics of soil obtained previously are $C_{m}=0.0342 \mathrm{Mpa}, \varphi_{m}=28.96^{\circ}$. The rest of the parameters values are founded by NAVFAC DM-7.2 [36]) as follows: $N_{q}=16.3, N_{c}=27.70, N_{\gamma}=16.90$

a) When the soil is saturated, the underground water is below the footing;

$$
q_{u}^{\prime}=1.673 \mathrm{MPa}, q_{\text {allowable }}=0.579 \mathrm{MPa}
$$

b) When the underground water is above the footing,

$$
q_{u}^{\prime}=1.514 \mathrm{MPa}, q_{\text {allowable }}=0.537 \mathrm{MPa}
$$

Having the means values of mechanical properties through the direct shearing 
test and considering that the bearing strength depends only on the depth $h$; Equation (12) will be an important tool for engineers, who will do only the dynamic penetrometer test and confront them with these values at any depth in order to have an idea of the range of the allowable bearing strength. This will have a direct impact of the dimensioning the structural elements and then cost and safety. The low value of $q_{\text {allowable }}$ shows that shallow foundations and isolated footings are prohibited in the border of coast, since they will be subjected to differential settlement. Meaning that particular precautions are required to avoid these drawbacks.

\section{Mathematical Model of Direct Shear Curve Test}

\subsection{Fitting of the Curves by the Least Square Method}

After obtaining the results previously presented by experiments, it is natural to establish an accurate mathematical model that will allow the estimation of the shear stress. When observing different curves obtained through the Casagrande box shown in Figures 14(a)-(c), each of ten points (P1...P10) has been grouped considering three normal loads Equation (1). As one can see, these graphs seem nonlinear with one peak on the $\mathrm{x}$-axis, the maximum representing the breaking stress. The goal in this section is to find the mean curve for the above mentioned normal loads and to determine the mean breaking stress for each one. And next make a comparison with the observational data and generalize the characteristics of the shearing test for the soil in the coast zone. We point out three methods of
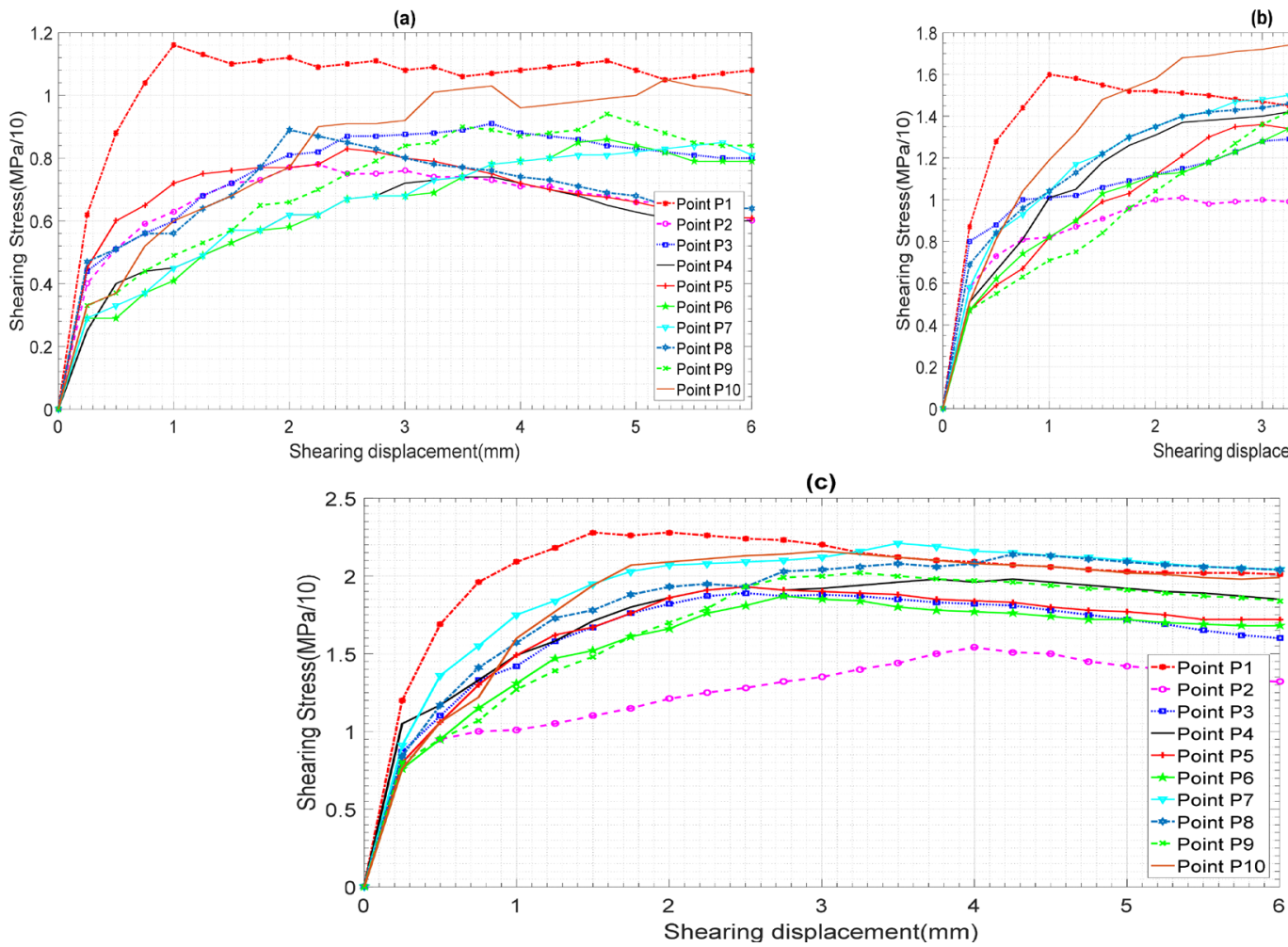

(b)

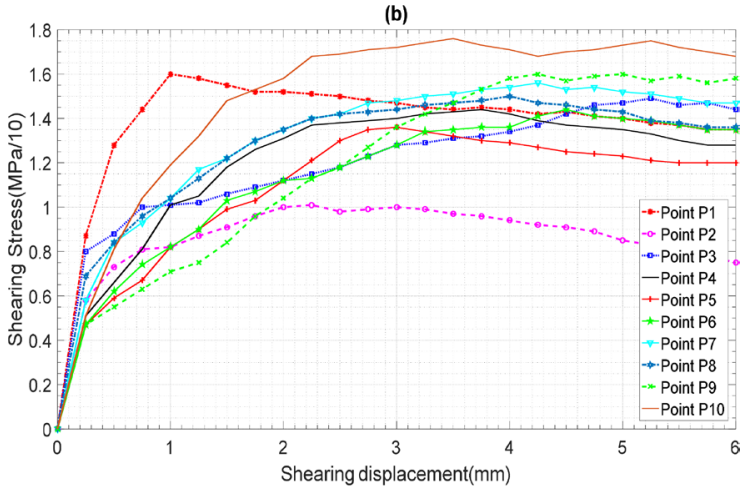


adjustments which highlight more details to our strategy: (a). Fourth order Fourier; (b). Second order exponential; (c): Nonlinear model, among many optimizations methods that are used. The best one being determined by these values: SSE sum of squares due to error, RMSE root mean squared error, which are called goodness of fitting

\subsubsection{Fourth-Order Fourier Method (FOFM)}

A Fourier series is a periodic function composed of harmonically related sinusoids, combined by a weighted summation. Let's denote $\mathrm{a}_{0}$ a mean value of $f(x)$. and $a_{i}, b_{i}$, the fundamental and the upper harmonics respectively, $\omega x$ denotes the corresponding phase for the variable $x$. To increase the accuracy of the approximation, the fourth-order equation has been chosen due to the fact that it is taking in account more information about the measure achieved. This interpolation is shown on Figure 15 corresponding to the three normal stresses with the function defined as follows:

$$
\begin{aligned}
\tau(x)= & a_{0}+a_{1} \cos (\omega x)+b_{1} \sin (\omega x)+a_{2} \cos (2 \omega x)+b_{2} \sin (2 \omega x) \\
& +a_{3} \cos (3 \omega x)+b_{3} \sin (3 \omega x)+a_{4} \cos (4 \omega x)+b_{4} \sin (4 \omega x),
\end{aligned}
$$

where $a_{i}, i=1,2,3,4, b_{i}, i=1,2,3,4$ and $\omega$ are constant real parameters to be determined.
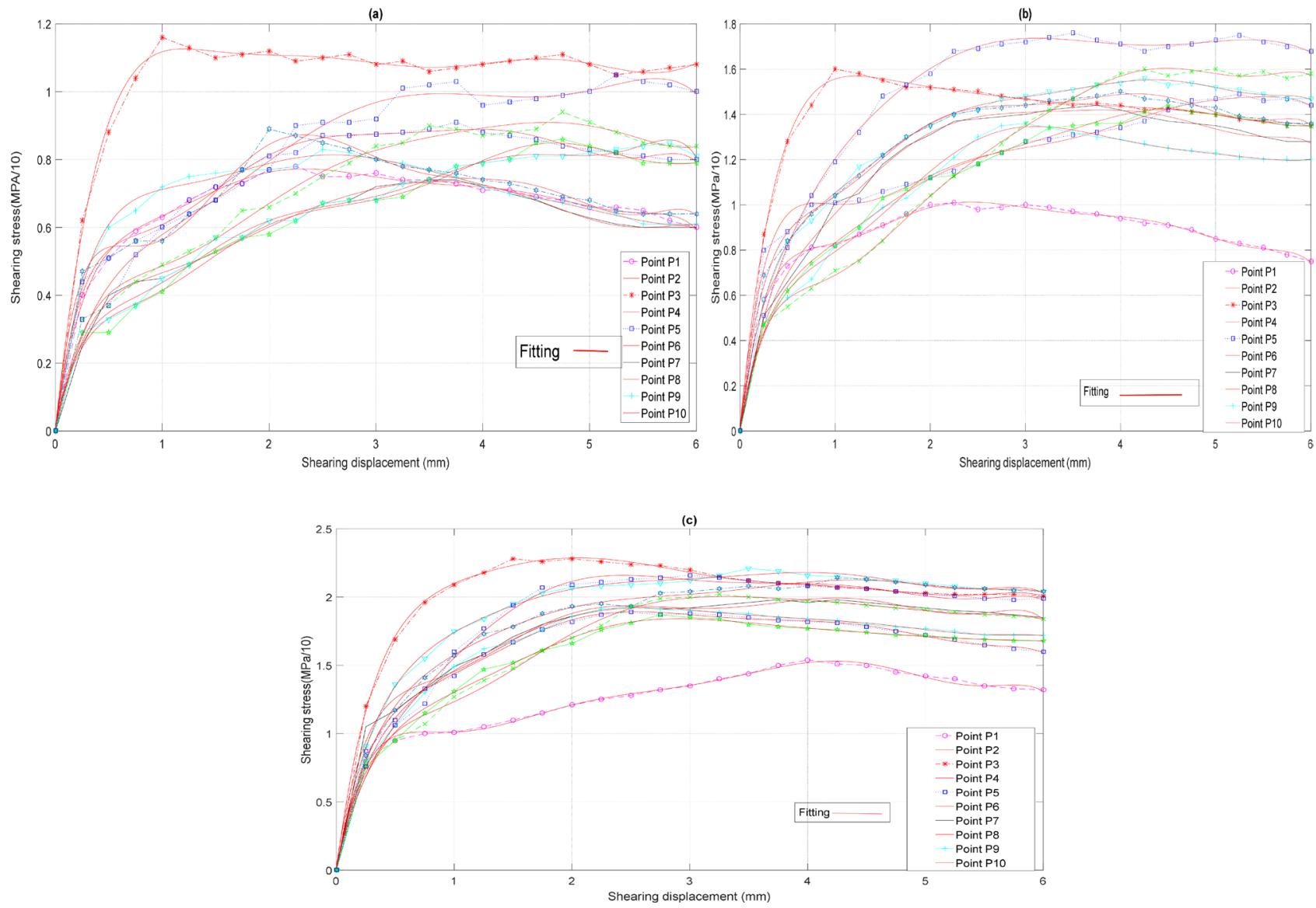

Figure 15. Pictures of the shearing test after fitting, (a) $0.1 \mathrm{Mpa}$, (b) $0.2 \mathrm{Mpa}$; (c) $0.3 \mathrm{Mpa}$ with FOFM. 


\subsubsection{Exponential Function Model (EFM)}

Exponential function is chosen as a combination of one or two exponential terms linearly independent.

This approximation takes into consideration all variations and curvatures in the parameters space. The graphs obtained are presented in Figure 16 by using the function defined as follows:

$$
\tau(x)=a \mathrm{e}^{\alpha x}+b \mathrm{e}^{\beta x},
$$

$a, b, \alpha, \beta$ being also the constant real parameters.

\subsubsection{Nonlinear Polynomial Function (NPFM)}

This method is considered in order to point out some complex aspects inputoutput which aren't linked by a constant. A nonlinear function is defined by terms having a variable of degree two or higher. The relevant function in view is presented as follows and the graphs obtained are shown in Figure 17.

$$
f(x)=\left(k x^{2}+m x+n\right) \mathrm{e}^{-x}+p+h(1+\sqrt{x})
$$

With $k, m, n, p, h$ the real constant parameters

\subsection{Comparative Study}

The main results from the methods presented above are recorded in Table 5.

The comparative analysis is made in order to choose the fitting method which
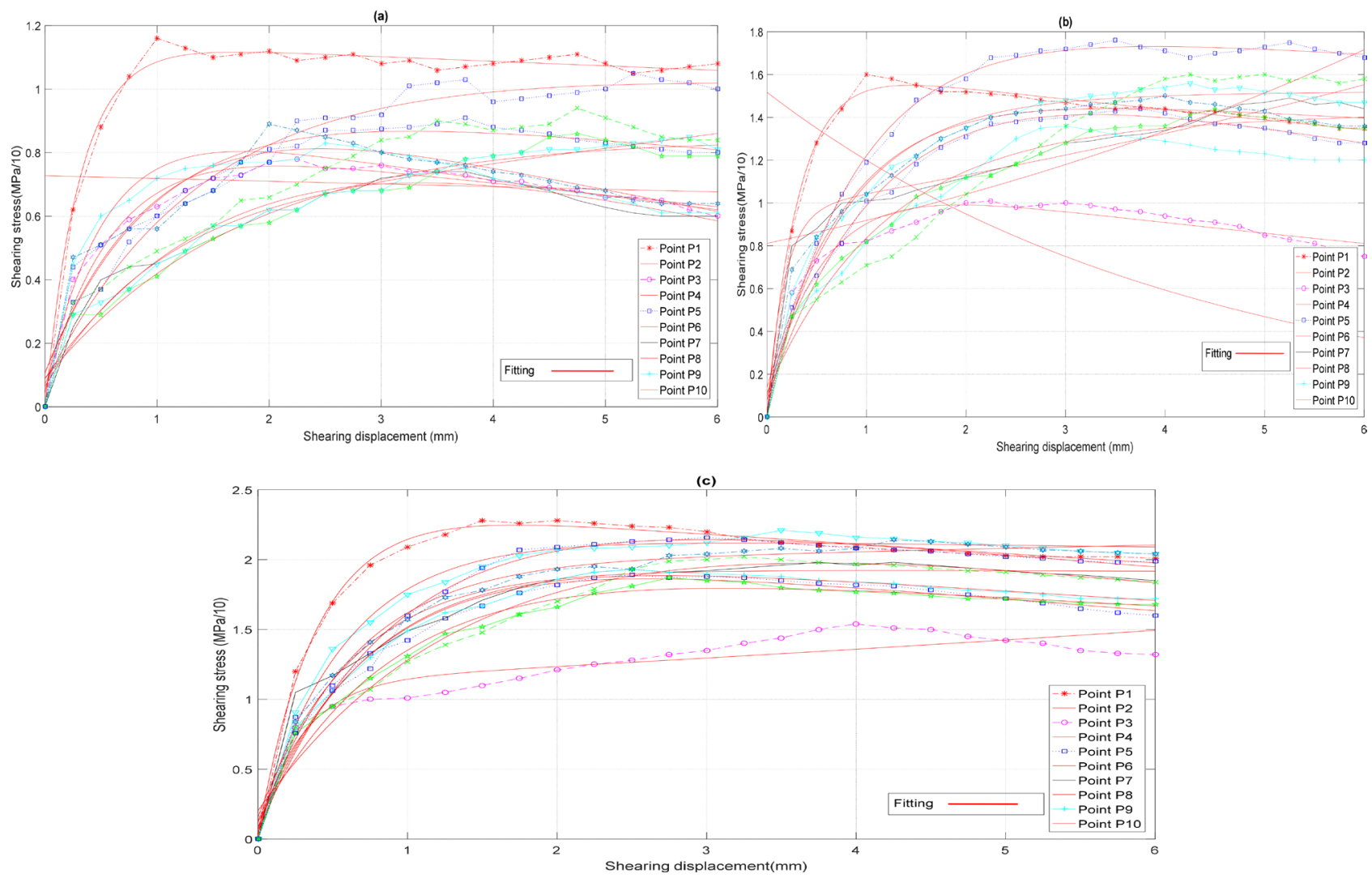

Figure 16. Pictures of the shearing test after fitting, (a) $0.1 \mathrm{Mpa}$, (b) $0.2 \mathrm{Mpa}$; (c) $0.3 \mathrm{Mpa}$ with EFM. 

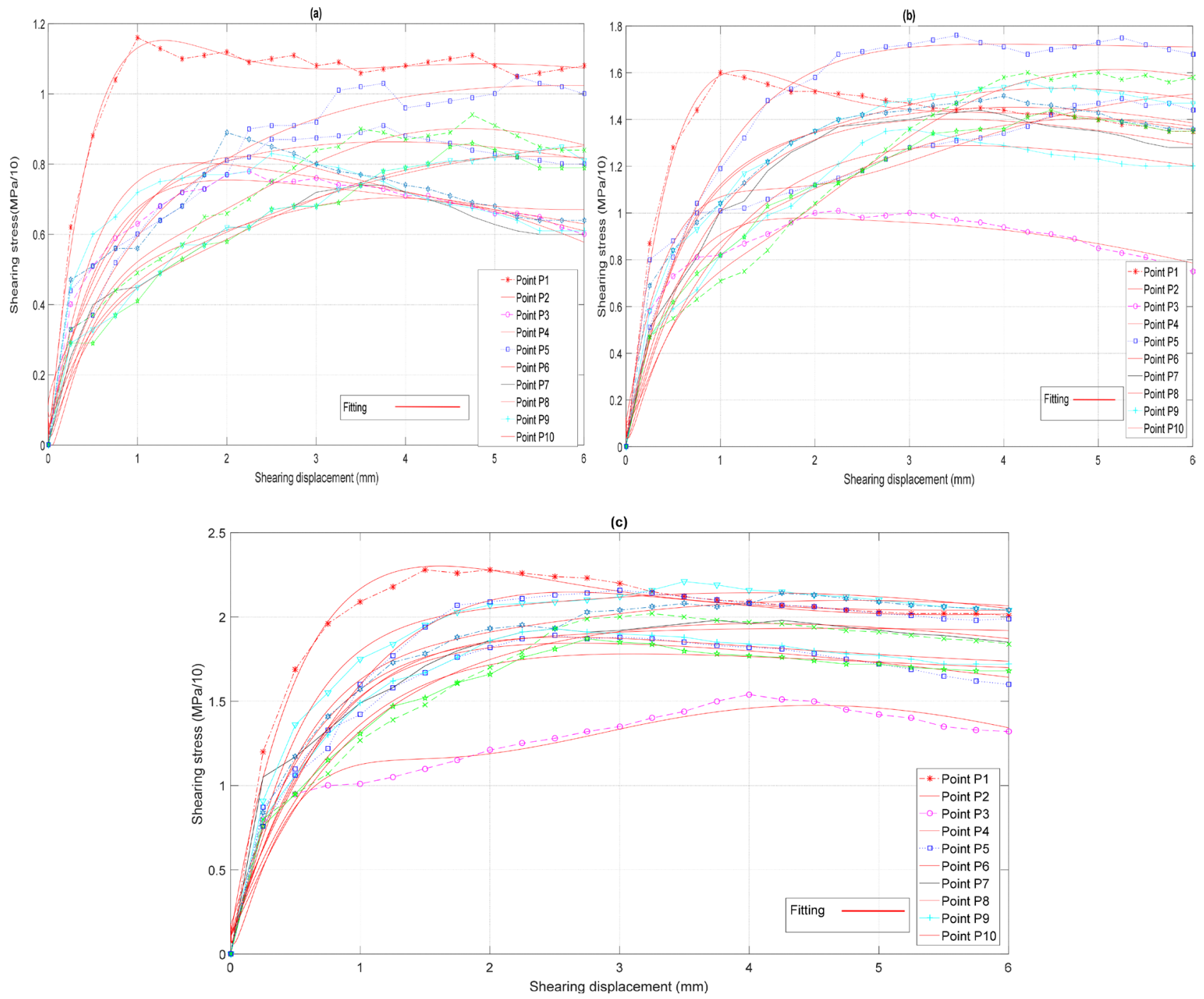

Figure 17. Pictures of the shearing test after fitting, (a) $0.1 \mathrm{Mpa}$, (b) $0.2 \mathrm{Mpa}$; (c) $0.3 \mathrm{MPa}$ with NPFM.

Table 5. Results summary from different fitting methods (FOFM, EFM, NPF)

\begin{tabular}{|c|c|c|c|}
\hline Fitting method & Normal stress & $\begin{array}{c}\text { Experimental breaking stress/ } \\
\text { Numerical breaking stress }(\mathrm{MPa})\end{array}$ & $\begin{array}{l}\text { Percentage/ } \\
\text { accuracy }\end{array}$ \\
\hline \multirow{3}{*}{$\begin{array}{c}\text { Fourier } \\
\text { fourth order }\end{array}$} & $0.1 \mathrm{MPa}$ & $\begin{array}{l}0.895 \\
0.890\end{array}$ & $0.56 \%$ \\
\hline & $0.2 \mathrm{MPa}$ & $\begin{array}{l}1.482 \\
1.478\end{array}$ & $0.27 \%$ \\
\hline & $0.3 \mathrm{MPa}$ & $\begin{array}{l}2.001 \\
2.003\end{array}$ & \\
\hline \multirow{2}{*}{ Exponential } & $0.1 \mathrm{MPa}$ & $\begin{array}{l}0.895 \\
0.878\end{array}$ & $1.90 \%$ \\
\hline & $0.2 \mathrm{MPa}$ & $\begin{array}{l}1.482 \\
1.453\end{array}$ & $1.96 \%$ \\
\hline
\end{tabular}




\begin{tabular}{cccc}
\hline & & 2.001 & $1.75 \%$ \\
& $0.3 \mathrm{MPa}$ & 1.966 & $1.45 \%$ \\
& $0.1 \mathrm{MPa}$ & 0.895 & \\
Nonlinear & & 0.882 & $1.89 \%$ \\
exponential & $0.2 \mathrm{MPa}$ & 1.482 & \\
& & 1.454 & $2.30 \%$ \\
& $0.3 \mathrm{MPa}$ & 2.001 & \\
\hline
\end{tabular}

represents the best approximation of the direct measure of the shear stress presented in the first part of this study. We clearly observe that for the fourth Fourier order method the values of the breaking stress are too closed to the experimental values. For the EFM and NPFM, the results are obtained and the output for each normal stress is derived but with low accuracy compared to the FOFM. From this analysis, it's obvious to reveal that the FOFM stands as the best fitting method to model the shear stress. Nevertheless, even though, the EFM and NPFM appear unsuitable for the coast, they may be exploited for other type of soils.

\section{Concluding Remark}

In this work, through a direct shear test, we have computed the characteristics of compressible soil (internal friction angle and the cohesion) and developed a corresponding mathematical model for the coastal area. Firstly, we provided by experiments the mechanical properties of the soils. It's come out as far as cohesion and frictional angle are concerned that the soil is a mixture of clay and sand with $0<C<0.48$ and cohesive $\left(\varphi=28.846^{\circ}\right)$ respectively. The case of Wouri borders in Cameroon is chosen to validate the results and the outcome has been satisfactory. These values will bring many conveniences to engineers of geotechnical field whenever they have identified that the soil is highly compressible. It will help to plan the construction of an appropriate structure with the soil conditions without having to make all tests for determining soil properties by doing only the penetrometer test and compare the values at different depths. Secondly, the comparative study has shown that the best fitting method to model the shear stress is the fourth order Fourier function. Some advantages can be listed through these results such as helping engineers to take decision faster and more accurately, typically offer convenience and cost advantages over other means of obtaining the required information on reality, helping civil engineers and architects to rapidly access the type and capacity of building as far as the elastic and plastic domains are known. It is relevant to point out that during this test the water pressure and drainage conditions are uncontrolled, additionally the non-uniformity of the failure plan. We then have only an approximation of pure shear 
specimen, so it will be interesting to carry out the same test with another test as triaxial method and compared the results.

\section{Conflicts of Interest}

The authors declare no conflicts of interest regarding the publication of this paper.

\section{References}

[1] Whitehouse, R.J.S., et al. (2000) Dynamics of Estuarine Muds. Thomas Telford, London. https://doi.org/10.1680/doem.28647

[2] Winterwerp, J.C. and van Kesteren, W.G.M. (2004) Introduction to the Physics of Cohesive Sediment in the Marine Environment. Elsevier, Amsterdam. https://doi.org/10.1016/S0070-4571(04)80004-9

[3] Thomas, K.A. (2015) The River-Border Complex: Governing Transboundary Flows in South.

[4] Thomas, K.A. (2016) The River-Border Complex: A Border-Integrated Approach to Transboundary River Governance Illustrated by the Ganges River and Indo-Bangladeshi Border. Water International, 42, 34-53. https://doi.org/10.1080/02508060.2016.1247236

[5] Donaldson, J.W. (2009) Where Rivers and Boundaries Meet: Building the International River Boundaries Database. Water Policy, 11, 629-644. https://doi.org/10.2166/wp.2009.065

[6] Lee, M., et al. (2013) Stress-Deformation and Compressibility Responses of Bio-Mediated Residuals Soils. Ecological Engineering, 60, 142-149. https://doi.org/10.1016/j.ecoleng.2013.07.034

[7] Kozicki, J., et al. (2013) Discrete Modelling Results of a Direct Shear Test for Granular Materials versus FE Results. Granular Matter, 15, 607-627. https://doi.org/10.1007/s10035-013-0423-y

[8] Xia, C., Yu, Q., Gui, Y., Qian, X., Zhuang, X. and Yu, S. (2018) Shear Behavior of Rock Joints under CNS Boundary Condition. Proceedings of GeoShanghai 2018 International Conference: Rock Mechanics and Rock Engineering, Shanghai, 27-30 May 2018, 263-274. https://doi.org/10.1007/978-981-13-0113-1 29

[9] Liu, Y., Xu, J., Yin, G. and Peng, S. (2016) Development of a New Direct Shear Testing Device for Investigating Rock Failure. Rock Mechanics and Rock Engineering, 50, 647-651. https://doi.org/10.1007/s00603-016-1099-5

[10] Larsson, J. and Flansbjer, M. (2020) An Approach to Compensate for the Influence of the System Normal Stiffness in CNS Direct Shear Tests. Rock Mechanics and Rock Engineering, 53, 2185-2199. https://doi.org/10.1007/s00603-020-02051-0

[11] Ouagni, M.S.T., et al. (2020) Determination of Mechanical Properties of Compressible Soil in Littoral's Region of Cameroon: Depths Study of Soils Bordering the Wouri River in Douala. American Scientific Research Journal for Engineering, Technology, and Sciences, 70, 139-151.

[12] Day, R.W. (2020) Foundation Engineering Handbook. 2nd Edition, McGraw-Hill Professional, New York.

[13] Harris, J.M. and Whitehouse, R.J.S. (2015) Scour Prediction in Non-Uniform Soils: Undrained Shear Stress and Erodibility. In: Cheng, Draper and An, Eds., Scour and Erosion, Taylor \& Francis Group, London. 
[14] Karl, T., Peck, R.B. and Mesri, G. (1996) Soil Mechanics in Engineering Practice. 3rd Edition, Wiley, New York.

[15] Alonso, E.E., Gens, A. and Josa, A. (1990) A Constitutive Model for Partially Saturated Soils. Géotechnique, 40, 405-430. https://doi.org/10.1680/geot.1990.40.3.405

[16] Terzaghi, K. and Peck, R.B. (1948) Soil Mechanics in Engineering Practice. Wiley, New York.

[17] Luna, R. and Jadi, H. (2000) Determination of Dynamic Soil Properties Using Geophysical Methods. Proceedings of the First International Conference on the Application of Geophysical and NDT Methodologies to Transportation Facilities and Infrastructure, St. Louis, 11-15 December 2000.

[18] Atkinson, J.H. and Sallfors, G. (1991) Experimental Determination of Soil Properties. Proceedings of the 10 th ECSMFE, Vol. 3, 915-956.

[19] Hsu, C.-C. and Vucetic, M. (2006) Threshold Shear Strain for Cyclic Pore-Water Pressure in Cohesive Soils. Journal of Geotechnical and Geoenvironmental Engineering, 132, 1325-1335. https://doi.org/10.1061/(ASCE)1090-0241(2006)132:10(1325)

[20] Assimaki, D., Kausel, E. and Whittle, A. (2000) Model for Dynamic Shear Modulus and Damping for Granular Soils. Journal of Geotechnical and Geoenvironmental Engineering, 126, 859-869. https://doi.org/10.1061/(ASCE)1090-0241(2000)126:10(859)

[21] George, B., Chuyong, G., et al. (2013) Nitrate and Ammonium Levels of Some Water Bodies and Their Interaction with Some Selected Properties of Soils in Douala Metropolis, Cameroon. African Journal of Environmental Science and Technology, 7, 648-656.

[22] (1985) American Society for Testing and Materials. Journal of Synthetic Lubrication, 2, 166-174. https://doi.org/10.1002/jsl.3000020206

[23] British Standards Institution (1999) BS 5930 Code of Practice for Site Investigations.

[24] Jia, J. (2018) Soil Dynamics and Foundation Modeling.

[25] Abanda, A. and Fokwa, P. (2018) Numerical Simulation of a Building Collapse on Sandy Clay of Douala City in Cameroon. Vol. 7.

[26] Surykanta (2015) How to Calculate Safe Bearing Capacity of Soil on Site.

[27] Craig, R.F. (2004) Craig's Soil Mechanics. 7th Edition, Spon Press, London. https://doi.org/10.4324/9780203494103

[28] Das, B.M. and Sobhan, K. (2013) Principles of Geotechnical Engineering. 8th Edition, CL Engineering, Ad Dikwani.

[29] Development of a True Triaxial Testing Apparatus (1993) Development of a True Triaxial Testing Apparatus: Reddy, K B; Saxena, S K; Budiman, J S Geotech Test JV15, N2, June 1992, P89-105. International Journal of Rock Mechanics and Mining Sciences \& Geomechanics Abstracts, 30, A78. https://doi.org/10.1016/0148-9062(93)90765-6

[30] Kayen, R.E., Mitchell, J.K., et al. (1992) Evaluation of SPT-, CPT-, and Shear WaveBased Methods for Liquefaction Potential Assessment Using Loma Prieta Data. Proceedings of 4th Japan-U.S. Workshop on Earthquake-Resistant Design of Lifeline Facilities and Countermeasures for Soil Liquefaction, Vol. 1, 177-204.

[31] Moss, R.E., Seed, R.B., Kayen, R.E., Stewart, J.P., Der Kiureghian, A. and Cetin, K.O. (2006) CPT-Based Probabilistic and Deterministic Assessment of in Situ Seismic Soil Liquefaction Potential. Journal of Geotechnical and Geoenvironmental Engineering, 132, 1032-1051. https://doi.org/10.1061/(ASCE)1090-0241(2006)132:8(1032) 
[32] Helwany, S. (2007) Applied Soil Mechanics.

[33] Prandtl, L. (1921) Hauptaufsätze: Über die Eindringungsfestigkeit (Härte) plastischer Baustoffe und die Festigkeit von Schneiden (On the Penetrating Strengths (Hardness) of Plastic Construction Materials and the Strength of Cutting Edges). Zeitschrift für Angewandte Mathematik und Mechanik, 1, 15-20. https://doi.org/10.1002/zamm.19210010102

[34] Terzaghi, K. (1943) Theoretical Soil Mechanics. Wiley, New York. https://doi.org/10.1002/9780470172766

[35] (1982) Naval Facilities Engineering Command Foundations and Earthquake Structures.

[36] Chai, J. (2000) Shallow Foundations. In: Chen, W.F. and Duan, L., Eds., Bridge Engineering Handbook, CRC Press, Boca Raton.

\section{Nomenclatures}

$C$ : Cohesion $(\mathrm{kPa})$;

$R$ : Coefficient of correlation;

$B_{c}, N_{q}, N_{Y}$ : Bearing capacity factors;

$S_{c}, S_{Y}$ : Shape factors;

$d_{c}, d_{y}, d_{q}:$ Depth factors;

$i_{c}, i_{y}, i_{q}$ : Load inclination factors;

$h$ : Depth of embedment of foundation (m);

\section{Greek Symbols}

$\gamma_{d}$ : Dry unit of the soil $\left(\mathrm{kN} / \mathrm{m}^{3}\right)$;

$\omega$ : Moisture content, percentage (\%);

$\sigma_{n}:$ Normal stress $\left(\mathrm{kN} / \mathrm{m}^{2}\right)$;

$\tau_{r}$ : Critical (breaking) shearing stress $\left(\mathrm{kN} / \mathrm{m}^{2}\right)$;

$\varphi$ : Angle of internal friction (degree);

$B^{\prime}$ : Effective width of a rectangular foundation $(\mathrm{m})$;

$\gamma^{\prime}$ : Effective unit weight of the soil $\left(\mathrm{kN} / \mathrm{m}^{3}\right)$. 